\title{
Animasi Interaktif Pengenalan Huruf Hijaiyah Berbasis Android
}

\author{
Rizky Januar Yudhistira ${ }^{1}$, Widiarina ${ }^{2}$ \\ ${ }^{1}$ Universitas Bina Sarana Informatika \\ e-mail: rijanyud@gmail.com \\ ${ }^{2}$ Universitas Bina Sarana Informatika \\ e-mail: widiarina11@bsi.ac.id
}

Cara Sitasi: Yudhistira , R. J., \& Widiarina, W. (2019). Animasi Interaktif Pengenalan Huruf Hijaiyah Berbasis Android. Jurnal Teknik Komputer, 65-70. doi:10.31294/jtk.v5i1.4287

\begin{abstract}
The development of animation that occurred in this era is very rapid. Animation is now an alternative in conveying the intent and purpose of information in digital media that is often used on computers and smartphones. As Muslims it is important to learn the Hijaiyah letter in the form of Arabic, because it is the beginning of the beginning of learning in Arabic sentences, and also in the fluent reading of the Qur'an along with its punctuation marks. Android smartphone users at this time are very diverse, including parents, young people, and children, but seeing in terms of function and benefits, smartphones can be interactive digital media that is useful and useful in knowing new knowledge and adding insight. In this case the author designs interactive animations to recognize letters and numbers hijaiyah and is equipped with games that are expected so that children do not get bored quickly, exercise memory, and are easy to understand. The method used in the development of this software uses the waterfall model. The concept of the animation system is made into a practical application and as an intermediary medium can be run on their gadgets.
\end{abstract}

Keywords: Multimedia, Interactive Animation, Letter Hijaiyah

\section{PENDAHULUAN}

Perkembangan animasi yang terjadi pada zaman ini sangatlah pesat, tidak terkecuali di Indonesia. Animasi saat ini sudah menjadi alternatif dalam menyampaikan maksud dan tujuan sebuah informasi dalam media digital yang sering digunakan pada komputer dan smartphone. Banyak sekali media digital berbentuk animasi yang diciptakan untuk memenuhi kebutuhan informasi yaitu para orang tua, anak muda, maupun anak-anak.

Pada umumnya di Indonesia, anak-anak akan lebih mudah mempelajari bahasa mereka sendiri yaitu bahasa Indonesia baik itu berupa kalimat maupun kosakata, namun yang tidak kalah pentingnya sebagai umat islam adalah mempelajari Huruf Hijaiyah yang berbentuk bahasa Arab karena merupakan awal dimulainya ilmu dalam mempelajari kalimat bahasa Arab dan juga bekal dalam fasihnya membaca Al Qur'an beserta tanda bacanya.

Pengguna smartphone Android pada zaman ini sangat beragam di antaranya orang tua, anak muda, dan anak-anak, namun melihat dari segi fungsi dan manfaatnya anak-anak seharusnya smartphone bisa menjadi media digital interaktif yang berguna dan bermanfaat dalam mengenal ilmu yang baru dan menambah wawasan. Karena jika melihat anak-anak usia dibawah 7 tahun sekarang ini sungguh sangat disayangkan hanya menjadikan smartphone Android sebagai alat permainan semata.

Menurut (Binanto, 2010) animasi adalah "usaha untuk membuat presentasi statis menjadi hidup". Dalam hal ini penulis merancang animasi interaktif mengenal huruf dan angka hijaiyah serta dilengkapi dengan permainan yang diharapkan agar anak tidak cepat bosan, melatih daya ingat, dan mudah dalam memahaminya. Sistem informasi pun dikemas dalam tampilan yang menarik dengan harapan agar anak semakin senang dalam memainkannya. Konsep sistem animasi tersebut dibuat menjadi sebuah aplikasi yang praktis dan sebagai media perantara nya dapat dijalankan pada gadget mereka.

Adapun beberapa teori konsep dasar animasi yang mendukung adalah sebagai berikut:

\section{Multimedia}

Multimedia merupakan kombinasi dari teks, gambar seni grafik, suara, animasi, dan elemen-elemen video yang dimanipulasi secara digital. Tampilan dan cita rasa dari proyek harus memuat konsistensi visual, hanya dengan menggunakan elemen-elemen yang 
mendukung pesan keseluruhan dari program multimedia merupakan suatu sistem komunikasi interaktif berbasis komputer yang mampu menciptakanm .menyajikan, dan mengakses kembali informasi berupa teks, grafik, suara, video, atau animasi.

Menurut (Darma, Jarot S, 2009) menyimpulkan bahwa: "Multimedia ditinjau dari bahasanya, terdiri dari 2 kata yaitu multi dan media. Multi memiliki arti banyak atau lebih dari satu. Sedangkan media merupakan bentuk jamak dari medium, juga diartikan sebagai saran, wadah, atau alat. Istilah multimedia sendiri dapat diartikan sebagai transmisi data dan manipulasi semua bentuk informasi, baik berbentuk kata-kata, gambar, video, musik, angka, atau tulisan tangan dimana dalam dunia komputer, bentuk informasi tersebut diolah dari dan dalam bentuk data digital".

Menurut (Budi Sutedjo, John Philio Simandjuntak, 2003) menyimpulkan bahwa:"Secara umum, multimedia diartikan sebagai kombinasi teks, gambar, seni grafik, animasi, suara, dan video. Aneka media tersebut digabungkan menjadi satu kesatuan kerja yang akan menghasilkan informasi dan memiliki nilai komunikasi interaktif yang sangat tinggi”.

Dari beberapa pendapat tersebut dapat disimpulkan bahwa multimedia adalah suatu sistem hubungan komunikasi interaktif melalui komponen yang mampu menyajikan dan menggabungkan data dalam bentuk gambar, video, fotografi, grafik, dan animasi dengan suara dan teks.

\section{Animasi}

Animasi interaktif adalah kumpulan gambar garis teks atau unsur pembentukan objek lain yang memberikan efek gerakan atau suara sehingga pengguna dapat menerima pesan-pesan yang disampaikan dan dapat melakukan timbal balik pada animasi.

Animasi itu sendiri memiliki arti gambar dua dimensi yang seolah-olah bergerak karena kelemahan mata yang selalu menyimpan atau mengingat di otak, imajinasi yang terlihat sebelumnya. Dalam animasi kartun, animasi diartikan sekumpulan gambar yang berubah sedikit demi sedikit, apabila ditampilkan secara berurutan dengan kecepatan teretntu.

Menurut (Madcoms, 2009) menyimpulkan bahwa:"Animasi adalah suatu gerakan yang dihasilkan oleh proses manipulasi visual. Animasi merupakan perubahan gambar dalam setiap waktu".

Menurut Vaughan dalam (Binanto, 2010) menyimpulkan bahwa:"Animasi adalah usaha untuk membuat presentasi statis menjadi hidup. Animasi merupakan perubahan visual sepanjang waktu”.

\section{Adobe Flash Professional CS 6}

Adobe Flash sudah dipakai sejak puluhan tahun yang lalu. Sebagian kalangan menggunakannya untuk membuat animasi untuk halaman website, prrofil perusahaan, game, dan lain-lain. Sekarang mulai berkembang penggunaan flash untuk pembuatan game di mobile device seperti handphone, PDA, dll. Menurut (Madcoms, 2012) menyatakan bahwa, "Adobe Flash adalah salah satu perangkat lunak komputer unggulan Adobe system, digunakan untuk membuat gambar vector maupun animasi gambar". Di dalam Flash, kita bisa memasukan rumus fisika, matematika, atau rumusrumus lainnya dalam bentuk Action Script.

\section{Adobe Photoshop CS 6}

Adobe Photoshop adalah program aplikasi desain yang berguna untuk mendesain gambar, mengedit image grafis, dan mengolah foto digital. Perangkat lunak komputer ini memiliki kelebihan pada kelengkapan fitur desain grafis dan olah fotonya. Toolbox yang tersedia dapat dipahami dan digunakan secara mudah dan cepat oleh pengguna yang masih belum berpengalaman sekalipun. Menurut (Jayan, 2010) "Photoshop merupakan aplikasi olah gambar digital yang dikembangkan oleh Adobe yang telah mencapai versi 13 atau disebut juga sebagai CS6 (Creative Suite 6), dengan beragam tool, filter, dan image adjustment yang dimilikinya, Photoshop menjadi pilihan utama untuk manipulasi foto".

\section{METODOLOGI PENELITIAN}

Dalam penelitian ini cara atau metode yang digunakan pada pembuatan aplikasi multimedia animasi interaktif ini yaitu:

\section{A. Metode Pengembangan Perangkat Lunak}

Metode yang digunakan pada pengembangan perangkat lunak ini menggunakan model water fall (Sommerville, 2003) yang terbagi menjadi 3 tahapan, yaitu:

1. Analisis dan Definisi Persyaratan

Mempelajari latar belakang masalah dan menguraikannya menjadi sebuah keinginan yang kuat untuk mencari solusi melalui pembuatan aplikasi berbasis Android.

2. Perancangan Sistem dan Perangkat Lunak Membuat storyboard, rancangan antar muka lalu menentukan gambar serta suara yang akan menjadi komponen dalam pembuatan aplikasi lengkap dengan efek agar animasi interaktif menjadi terlihat lebih menarik untuk dijalankan.

3. Implementasi dan Pengujian Unit Ketika animasi dan efek sudah lengkap maka selanjutnya di compile menjadi bentuk .apk yang 
siap diuji melalui smartphone Android maupun software Bluestack pada komputer dan notebook menggunakan blackbox testing.

\section{B. Teknik Pengumpulan Data}

Teknik pengumpulan data yang penulis gunakan adalah:

\section{Pengamatan Langsung}

Dalam metode ini penulis melakukan pengamatan objek penelitian secara langsung kepada anak-anak berusia dibawah 7 tahun di lingkungan sekitar rumah di perumahan Pondok Ungu Permai Blok G2.

2. Studi Pustaka

Penulis mempelajari dan membaca buku-buku sebagai bahan acuan penulisan Tugas Akhir ini dengan mengembangkan pengetahuan penulis, juga mempelajari e-book dan video yang berisi tutorial pembuatan aplikasi untuk dijalankan pada smartphone android, kemudian mencari sumber gambar melalui browser internet.

\section{HASIL DAN PEMBAHASAN}

Telepon Seluler adalah alat komunikasi yang kini sudah banyak digunakan oleh masyarakat. Dan seiring perkembangan zaman kini anak usia dini sudah mengerti mengenai bagaimana cara menggunakan telepon seluler. Saat telepon seluler digunakan oleh anak usia dini tentu mereka sangat besar rasa ingin tahunya dengan berbagai aplikasi di telepon seluler, untuk mendukung pertumbuhan anak usia dini dengan menambah ilmu pengetahuan maka penulis membuat media pengenalan melalui aplikasi android. Pembuatan media pengenalan sekaligus permainan ini diharapkan dapat memberikan suatu hiburan sekaligus memotivasi anak-anak untuk lebih mudah mengerti dan cepat menguasai huruf serta angka hijaiyah. Dan diharapkan dapat memberikan rasa semangat untuk membantu pertumbuhan dan perkembangan jasmani dan mental. Selain itu agar anak memiliki kesiapan dalam memasuki dunia bahasa arab yang lebih kompleks.

Dalam hal ini penulis merancang animasi interaktif pengenalan huruf hijaiyah, serta pengenalan harokat dimana animasi interaktif ini dapat dijalankan pada smartphone. Animasi interaktif ini diharapkan agar anak lebih cepat tanggap dan mudah mengerti serta tidak cepat bosan dalam mengenal huruf hijaiyah.

\section{Rancangan Storyboard}

Berikut ini adalah gambaran dari Storyboard animasi interaktif pengenalan huruf hijaiyah:

a. Storyboard Halaman Pembuka

\begin{tabular}{|c|c|c|}
\hline Visual & Sketsa & Audio \\
\hline $\begin{array}{c}\text { Dalam frame ini } \\
\text { terdapat halaman } \\
\text { pembuka sebelum } \\
\text { melanjutkan ke halaman } \\
\text { menu utama aplikasi }\end{array}$ & Judul & \\
& Mulai & \\
\hline
\end{tabular}

Gambar 1. Storyboard Halaman Pembuka

b. Storyboard Menu Utama

\begin{tabular}{|c|c|c|c|}
\hline Visual & Sketsa & & Audio \\
\hline \multirow{7}{*}{\begin{tabular}{||c} 
Dalam frame ini \\
terdapat 6 menu yang \\
bisa dipilih oleh \\
pengguna antara lain: \\
Pengenalan Huruf \\
Hijaiyah, Pengenalan \\
Harokat, Latihan Soal, \\
Bantuan, Permainan, \\
Profil, dan 1 buah \\
tombol untuk keluar dari \\
aplikasi.
\end{tabular}} & Judul & Keluar & \multirow{7}{*}{ arabic.wav } \\
\hline & Pengenalan Huruf Hijaiyah & & \\
\hline & Pengenalan Harokat & & \\
\hline & Latihan Soal & & \\
\hline & Bantuan & & \\
\hline & Permainan & & \\
\hline & Profil & & \\
\hline
\end{tabular}

Gambar 2. Storyboard Menu Utama

c. Storyboard Halaman Pengenalan Huruf Hijaiyah

\begin{tabular}{|c|c|c|c|}
\hline Visual & Skets & & Audio \\
\hline $\begin{array}{c}\text { Dalam frame ini terdapat } \\
\text { tampilan yang menampilkan } \\
30 \text { huruf hijainah alif--ya dan } \\
\text { terdapat } 1 \text { tombol yang } \\
\text { berfungsis sebagai kembali, } \\
\text { ketika satu persatu huruf di } \\
\text { klik maka akan ditampilan } \\
\text { kembali di kotak beserta } \\
\text { nama huruf tersebut dan } \\
\text { mengeluarkan suara sesuai } \\
\text { huruf yang di klik. }\end{array}$ & Gambar & Kembali & \begin{tabular}{|l} 
Alif,ba, ta,tsa \\
jim,ha,kha,dal \\
dzal,ra zai, sin \\
syin,shod,dhod \\
tho,zho,ain,ghain \\
;fa,qof,kaf,lam \\
,mim,nun,wau, \\
ha',lamalif \\
hamzah,ya \\
Semua format \\
.wav
\end{tabular} \\
\hline
\end{tabular}

Gambar 3. Storyboard Halaman Pengenalan Huruf Hijaiyah

d. Storyboard Pengenalan Harokat

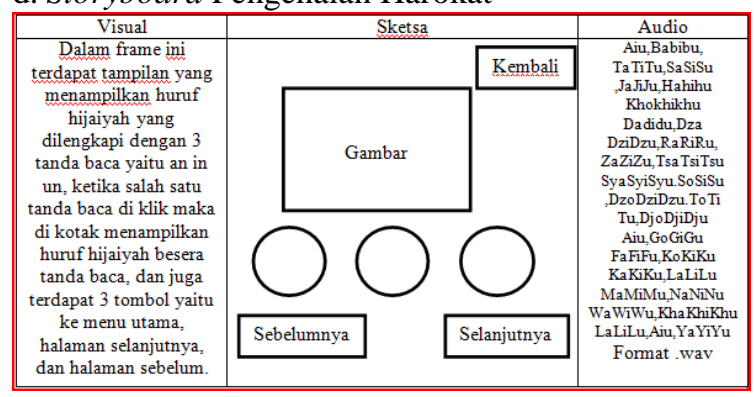

Gambar 4. Storyboard Pengenalan Harokat

e. Storyboard Soal Latihan

\begin{tabular}{||c|c|c||}
\hline Visual & \multicolumn{1}{|c||}{ Sketsa } & Audio \\
\hline $\begin{array}{c}\text { Dalam frame ini akan } \\
\text { ditampilkan 6 huruf } \\
\text { hijaiyah yang dimana 1 } \\
\text { huruf hijaiyah sebagai } \\
\text { soal latihan, dan 5 huruf } \\
\text { lainnya sebagai jawaban } \\
\text { yang harus disamakan } \\
\text { dengan soal dari latihan, } \\
\text { jika benar skomya 20 } \\
\text { dan jika salah skor 0. }\end{array}$ & \multicolumn{1}{|c||}{ Judul } & \\
\hline
\end{tabular}

Gambar 5. Storyboard Soal Latihan 
f. Storyboard Penilaian Latihan Soal

\begin{tabular}{||c|c|c||}
\hline Visual & \multicolumn{1}{|c||}{ Sketsa } & Audio \\
\hline Dalam frame ini akan & \multicolumn{1}{|c||}{ Judul } & \\
tampil skor penilaian \\
dari hasil latihan soal ke \\
1 yaitu berupa nama \\
pemain dan total skor, \\
lalu ada 2 tombol yaitu \\
lanjut ke latihan soal ke \\
2 dan kembali ke menu \\
utama.
\end{tabular}

Gambar 6. Storyboard Penilaian Latihan Soal

g. Storyboard Halaman Permainan

\begin{tabular}{|c|c|c|c|c|}
\hline Visual & \multicolumn{3}{|c|}{ Sketsa } & Audio \\
\hline \multirow{5}{*}{$\begin{array}{l}\text { Dalam frame ini } \\
\text { terdapat tampilan } \\
\text { permainan yang bertema } \\
\text { mencocokan huruf } \\
\text { hijaiyah dan diberi batas } \\
\text { waktu dalam menjawab } \\
\text { permainan tersebut, jika } \\
\text { salah muncul pilihan } \\
\text { coba lagi dan jika benar } \\
\text { maka permainan selesai. }\end{array}$} & & Judul & & \multirow{3}{*}{ game.wav } \\
\hline & Teks & Teks & Teks & \\
\hline & & & & \\
\hline & & & & \\
\hline & Judul & \multicolumn{2}{|c|}{ Batas Waktu } & \\
\hline
\end{tabular}

Gambar 7. Storyboard Halaman Permainan

h. Storyboard Halaman Berhasil

\begin{tabular}{|c|c|c|}
\hline \hline Visual & Sketsa & Audio \\
\hline $\begin{array}{c}\text { Dalam frame ini akan } \\
\text { ditampilan tulisan } \\
\text { berhasil menyelesaikan } \\
\text { permainan dan 1 buah } \\
\text { tombol yaitu kembali ke } \\
\text { menu utama. }\end{array}$ & Teks & \\
& Kembali & \\
& game.wav \\
\hline
\end{tabular}

Gambar 8. Storyboard Halaman Berhasil

\section{Rancangan Antar Muka}

Menjelaskan rancangan antarmuka (Interface) yang ada dalam animasi interaktif mengenal huruf hijaiyah berbasis android pada anak usia dibawah 7 tahun.

a. Rancangan Halaman Pembuka

Tampilan ini berisi teks judul aplikasi dan 1 tombol mulai yang jika di klik akan menuju ke menu utama aplikasi yang berisi berbagai macam menu.

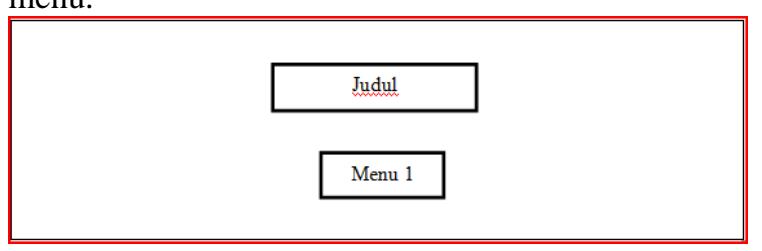

Gambar 9. Rancangan Halaman Pembuka

\section{b. Rancangan Menu Utama}

Tampilan ini berisi 6 tombol menu utama yaitu, tombol pengenalan huruf hijaiyah, pengenalan harokat, latihan soal, bantuan, permainan, dan profil, dan 1 buah tombol untuk keluar dari aplikasi.

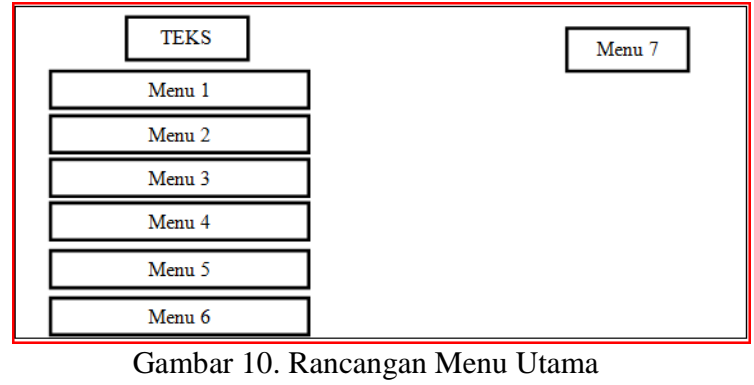

c. Rancangan Pengenalan Huruf Hijaiyah Tampilan ini berisi 30 tombol huruf hijaiyah, 1 kolom gambar huruf hijaiyah untuk menampilkan huruf beserta teksnya, dan 1 buah tombol kembali ke menu utama.

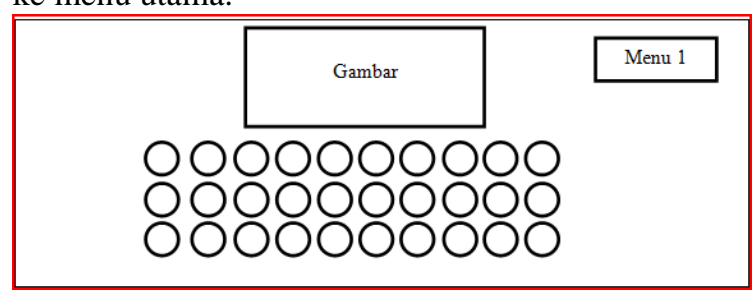

Gambar 11. Rancangan Pengenalan Huruf Hijaiyah

d. Rancangan Menu Pengenalan Harokat

Tampilan ini hanya berisi 3 tombol harokat, 1 buah kolom gambar untuk menampilan huruf hijaiyah beserta harokat yang di klik, dan 3 tombol yang berfungsi untuk ke halaman selanjutnya atau halaman sebelumnya dan tombol kembali ke menu utama.

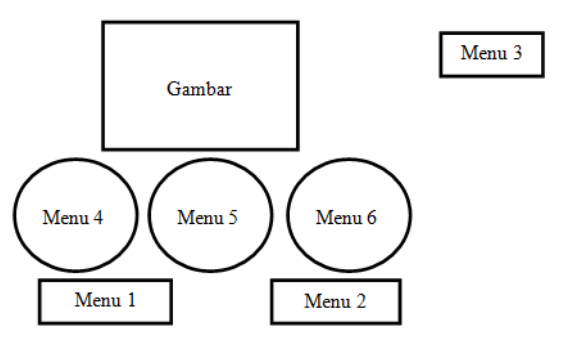

Gambar 12. Rancangan Menu Pengenalan Harokat

e. Rancangan Menu Latihan Soal

Rancangan menu latihan 1dan latihan 2 ini berisi 5 tombol yang salah satunya merupakan jawaban yang benar atas soal huruf hijaiyah yang ditampilkan, di menu ini tidak terdapat menu kembali ke menu utama.

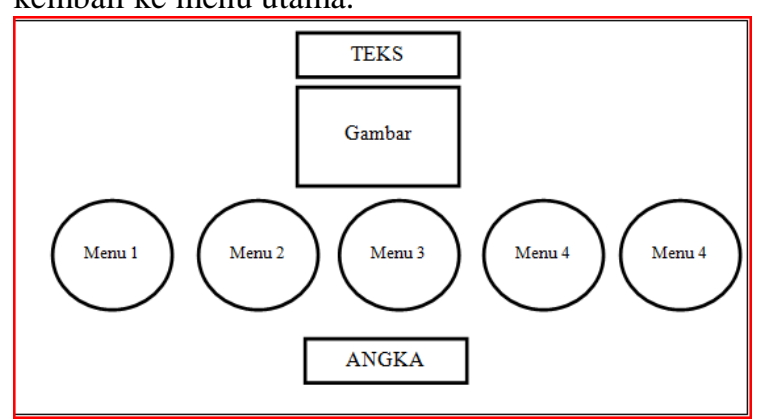

Gambar 13. Rancangan Menu Latihan Soal 
f. Rancangan Penilaian Latihan Soal

Rancangan penilaian latihan soal 1 ini berisi nama pemain yang telah disimpan pada halaman awal latihan soal beserta skor yang diraih pada latihan soal 1, dan 2 tombol yang berfungsi untuk melanjutkan ke latihan soal 2 atau kembali ke menu utama.

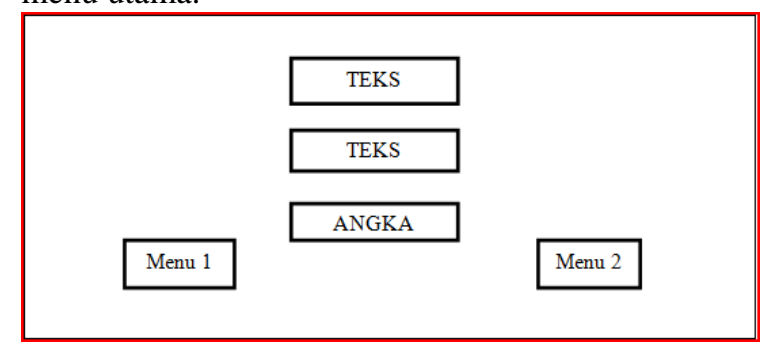

Gambar 14. Rancangan Penilaian Latihan Soal

g. Rancangan Menu Permainan

Rancangan permainan ini tidak terdapat tombol keluar ke menu utama karena memang fokus dan diharuskan untuk mengikuti permainan hingga selesai, dan terdapat 3 tombol jawaban berbentuk huruf yang harus di drag ke dalam teks hijaiyah yang sesuai dengan huruf.

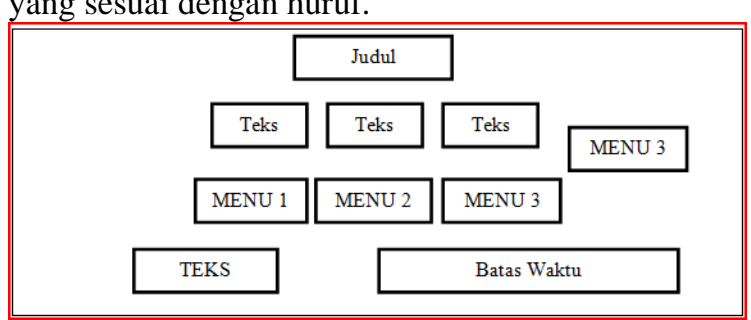

Gambar 15. Rancangan Menu Permainan

h. Rancangan Halaman Permainan Berhasil Rancangan halaman permainan berhasil ini hanya terdapat 1 tombol untuk kembali ke menu utama.

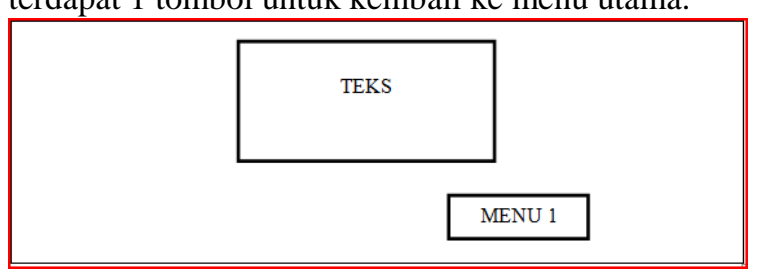

Gambar 16. Rancangan Halaman Permainan Berhasil

\section{Implementasi}

a. Tampilan Halaman Pembuka

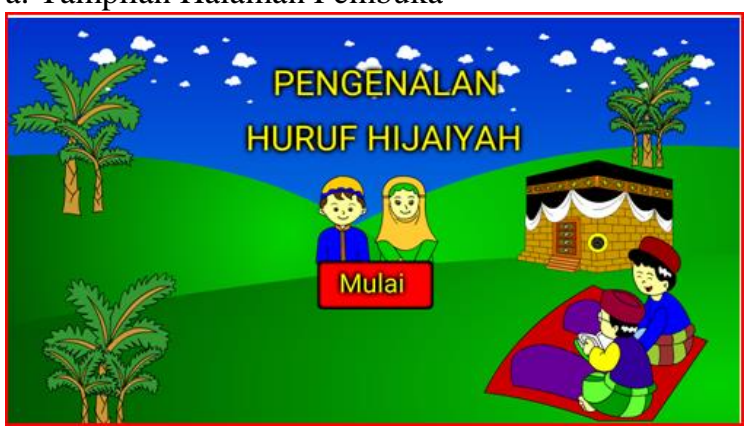

Gambar 17. Tampilan Halaman Pembuka b. Tampilan Menu Utama

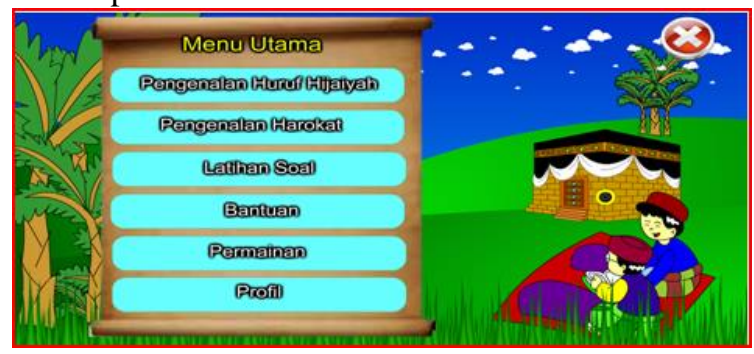

Gambar 18. Tampilan Menu Utama

c. Tampilan Pengenalan Huruf Hijaiyah

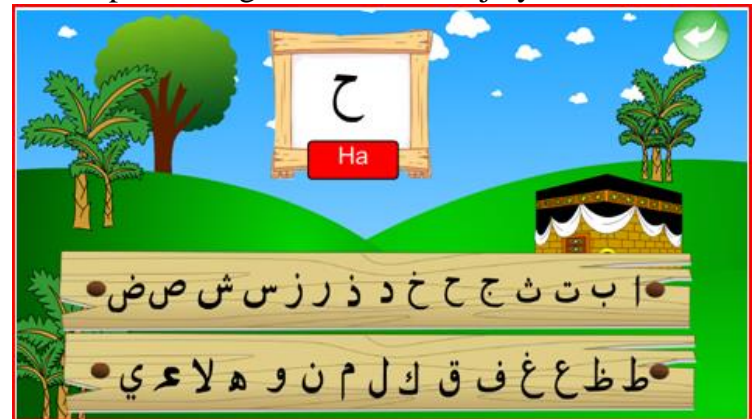

Gambar 19. Tampilan Pengenalan Huruf Hijaiyah

d. Tampilan Pengenalan Halaman Harokat

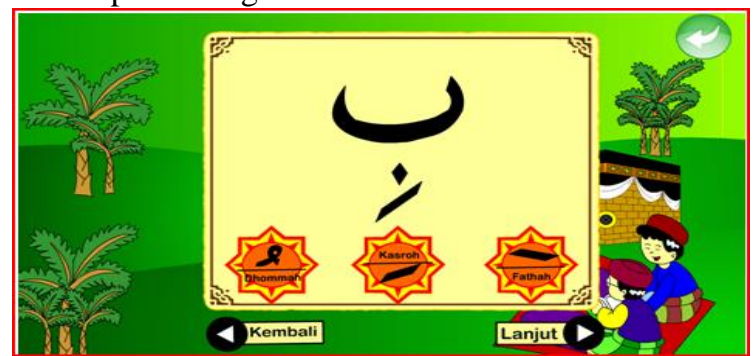

Gambar 20. Tampilan Pengenalan Halaman Harokat

e. Tampilan Halaman Latihan Soal

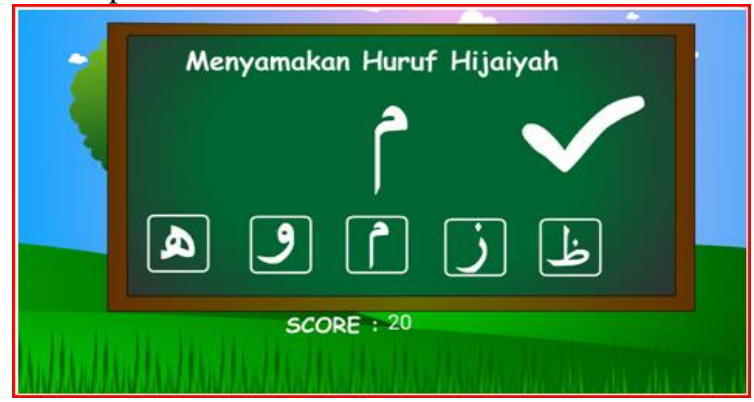

Gambar 21. Tampilan Halaman Latihan Soal

f. Tampilan Penilaian Latihan Soal

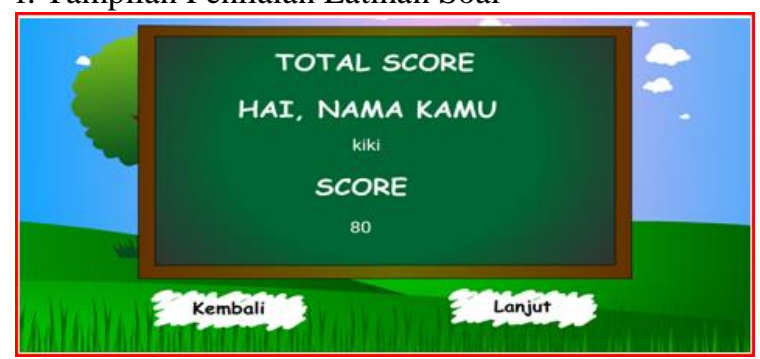

Gambar 22. Tampilan Penilaian Latihan Soal 


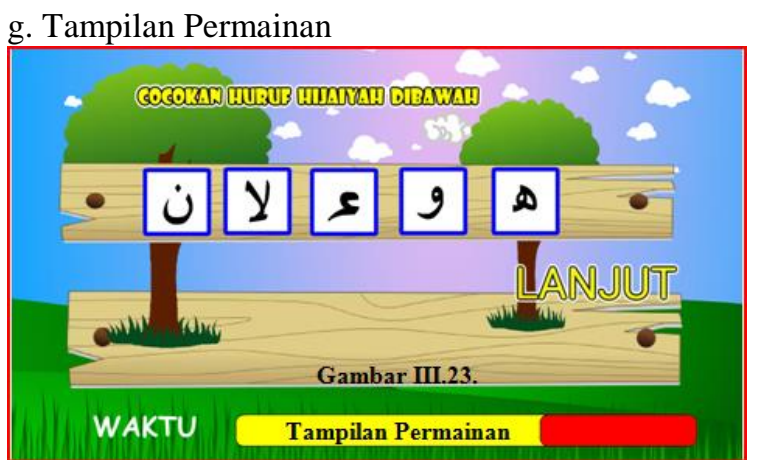

Gambar 23. Tampilan Permainan

h. Tampilan Permainan Berhasil

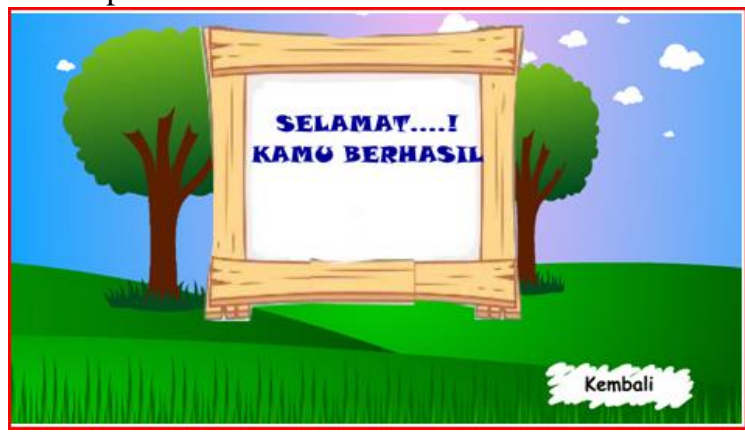

Gambar 24. Tampilan Permainan Berhasil

\section{Pengujian Unit}

Pengujian terhadap program yang dibuat menggunakan Blackbox testing yang fokus terhadap proses masukan dan keluaran program.Contoh pengujian terhadap Tombol Halaman Pembuka dapat dilihat pada Tabel 1.

Tabel 1. Pengujian Tombol Halaman Pembuka

\begin{tabular}{llll}
\hline Inpu & Proses & Outp & Vali \\
$\mathrm{t}$ & & ut & dasi \\
Tom & btn_masuk.addEvent & Tamp & Sesu \\
bol & Listener & ilan & ai \\
Mul & (MouseEvent.CLIC & Menu & Utam \\
ai & K,masukk); & a & \\
& function & \\
& masukk(event:Mous & \\
& eEvent):void & \\
& \{SoundMixer.stopAl & \\
& 1(); & \\
& MovieClip(root).got & \\
& oAndStop(3); & \\
& &
\end{tabular}

\section{KESIMPULAN}

Aplikasi animasi interaktif tentang pengenalan huruf hijaiyah, pengenalan harokat huruf hijaiyah, latihan soal, serta permainan berbasis android diperuntukkan untuk anak usia 5 sampai 7 tahun agar tidak cepat bosan dan lebih semangat dalam mengenal huruf hijaiyah.. Aplikasi ini juga mempermudah anak usia dini dalam mengenal dan memahami tentang huruf hijaiyah yang bertipe visual dimana mereka bisa lebih memahami huruf hijaiyah dan harokat dengan gambaran yang jelas. Dari segi kegunaan, aplikasi pengenalan huruf hijaiyah ini bisa menjadi sarana alternatif selain melalui buku untuk mengenal huruf hijaiyah dan harokatnya. Untuk kedepannya media pengenalan ini diharapkan dapat dikembangkan lebih jauh lagi seperti mengenal warna dan angka dalam bahasa arab agar lebih menarik dan menambah wawasan anak.

\section{REFERENSI}

Binanto, I. (2010). Multimedia Digital Dasar Teori dan Pengembangannya. Yogyakarta: Andi.

Budi Sutedjo, John Philio Simandjuntak, A. A. S. (2003). . I-CRM Membina Relasi Dengan Pelanggan.Com. Yogyakarta: ANDI.

Darma, Jarot S, S. A. (2009). Buku Pintar Menguasai Multimedia. Jakarta: Media Kita.

Jayan. (2010). 7 Jam Belajar Interaktif Photoshop CS6 untuk Orang Awam. Palembang: Maxikom.

Madcoms. (2009). Panduan Lengkap Editing Video dengan Premiere Pro CS4. Yogyakarta: Andi.

Madcoms. (2012). Kupas Tuntas Adobe Flash Professional CS6. Yogyakarta: Andi.

Sommerville, I. (2003). Software Engineering Rekayasa Perangkat Lunak. Jakarta: Erlangga.

\section{PROFIL PENULIS}

Rizky Januar Yudhistira

Mahasiswa program studi manajemen informatika AMIK BSI Bekasi.

\section{Widiarina}

Dosen Universitas Bina Sarana Informatika program studi Sistem Informasi 